\title{
Analysis of Thermal Behavior of High Frequency Transformers Using Finite Element Method
}

\author{
Hossein Babaie, Hassan Feshki Farahani \\ Ashtian Branch, Islamic Azad University, Tehran, Iran. \\ Email: \{hbabaei2002,hfeshki\}@yahoo.com \\ Received August $15^{\text {th }}, 2010$; revised September 17 $7^{\text {th }}, 2010$; accepted September $20^{\text {th }}, 2010$.
}

\begin{abstract}
High frequency transformer is used in many applications among the Switch Mode Power Supply (SMPS), high voltage pulse power and etc can be mentioned. Regarding that the core of these transformers is often the ferrite core; their functions partly depend on this core characteristic. One of the characteristics of the ferrite core is thermal behavior that should be paid attention to because it affects the transformer function and causes heat generation. In this paper, a typical high frequency transformer with ferrite core is designed and simulated in ANSYS software. Temperature rise due to winding current (Joule-heat) is considered as heat generation source for thermal behavior analysis of the transformer. In this simulation, the temperature rise and heat distribution are studied and the effects of parameters such as flux density, winding loss value, using a fan to cool the winding and core and thermal conductivity are investigated.
\end{abstract}

Keywords: High Frequency Transformers, Thermal Behavior, Ferrite Core and Finite Element Analysis

\section{Introduction}

Magnetic components design plays a key role in achieving high efficiency, low volume and reasonable price of power electronic equipment. With the advent of higher switching frequencies and power densities in power electronic circuits, it is important to ensure that magnetic components, such as transformers and inductors, operate within the limits defined by the thermal specifications of the circuit. Temperature rise depends on the power losses through the laws of the heat transfer theory. In order to obtain an accurate value of the maximum temperature of the device during the design process, it is necessary to apply an accurate thermal model. It is necessary of a trade-off between thermal distribution accuracy (directions through heat transfer is considered, constant thermal properties, feedback with the magnetic model, steady state models, etc) and the complexity of the thermal model that is obtained.

Losses in the magnetic components are important design parameters. In many high-frequency designs, magnets are limited by their losses. Thus, it is extremely important for the designer to have a good practical model for estimating the losses under various excitations that are frequently encountered in power electronics design. There are two major components of the losses [1-9] in a magnetic component: the core loss (i.e., the losses in the magnetic material which is used as core) and the winding losses. High-frequency conductor losses for power electronics applications have been considered by a number of authors [8,9]. There are models provided by different manufacturers [10-12], that are synthesized in a simple expression for the calculation of the temperature rise. They provide the average temperature in the outer surface of the device.

Most of thermal models for magnetic components are analytical and assume 1D heat transfer [13-15]. These models are based on thermal networks and commonly consider only steady state, constant thermal properties, concentrated and uniform power losses and no thermal feedback with the electric properties. However, the thermal distribution is $2 \mathrm{D} / 3 \mathrm{D}$ for most of cases, even if the magnetic field exhibits a 1D distribution.

The thermal design is usually somewhat neglected as it is often not clear which theory and coefficients should be used and experiments are time consuming. In this article, by designing a typical high-frequency transformer with ferrite core, its thermal behavior is investigated. Many parameters such as flux density, winding loss value, using a fan to cool the winding and core and thermal conductivity have effects on the ferrite temperature which is simulated with ANSYS software.

\section{Calculating the Heat Generation Caused by Winding and Investigating Its Effective Parameters}

Heat generating sources are transformer windings which 
generate heat by passing the current and this heat is transmitted to other parts. For a winding with resistance $\mathrm{R}_{\mathrm{j}}$, the power loss can be written as:

$$
P_{c u, j}=I_{j}^{2} R_{j}
$$

Which the $\mathrm{j}^{\text {th }}$ winding resistance is as follow:

$$
R_{j}=\rho \frac{l_{j}}{A_{w, j}}
$$

Where:

$$
\begin{gathered}
l_{j}=n_{j}(M L T) \\
A_{w, j}=\frac{W_{A} K_{u} \alpha_{j}}{n_{j}}
\end{gathered}
$$

In Equation (3), MLT is mean length per turn ( $\mathrm{cm})$. By considering Equation (2) to Equation (4), the power loss of $\mathrm{j}^{\text {th }}$ winding is as follow:

$$
P_{c u, j}=\frac{n_{j}^{2} i_{j}^{2} \rho(M L T)}{W_{A} K_{u} \alpha_{j}}
$$

And the total power dissipation is the sum of the power losses for each winding:

$$
P_{c u, t o t}=\frac{\rho(M L T)}{W_{A} K_{u}} \sum_{j=1}^{k}\left(\frac{n_{j}^{2} I_{j}^{2}}{\alpha_{j}}\right)
$$

The loss in winding is optimal providing that [16]:

$$
P_{c u, t o t}=\frac{\rho(M L T)}{W_{A} K_{u}} \sum_{j=1}^{k}\left(n_{j} I_{j}\right)
$$

According to Equation (7), it can be found out that the power loss or generated heat depends on parameters such as $\rho$ (wire effective resistivity), $K_{u}$ (winding fill factor), turns, winding current and MLT (mean length per turn). So, these are effective parameters on generation heat source. In a transformer, if the primary voltage is like Figure 1, then the following equations will be written:

$$
\begin{gathered}
\lambda_{1}=\int_{t_{1}}^{t_{2}} v_{1}(t) d t \\
B_{\max }=\frac{\lambda_{1}}{2 n_{1} A_{c}} \Rightarrow n_{1}=\frac{\lambda_{1}}{2 B_{\max } A_{c}}
\end{gathered}
$$

By substituting Equation (9) in Equation (7), the result can be written as:

$$
P_{c u}=\frac{\rho(M L T) I_{\text {tot }}^{2}}{W_{A} K_{u}} n_{1}^{2}=\underbrace{\left(\frac{\rho \lambda_{1}^{2} I_{\text {tot }}^{2}}{k_{u}}\right)}_{A} \underbrace{\left(\frac{(M L T)}{W_{A} A_{c}^{2}}\right)}_{B} \underbrace{\left(\frac{1}{B_{\max }^{2}}\right)}_{C}(10)
$$

where:

$$
I_{t o t}=\sum_{j=1}^{k} \frac{n_{j}}{n_{1}} I_{j}
$$

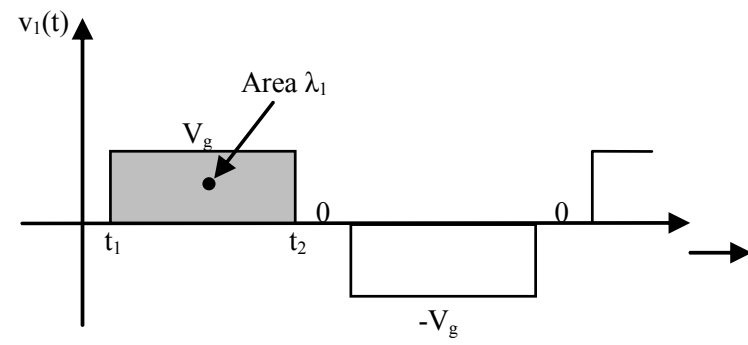

Figure 1. Transformer primary voltage.

Equation (10) consists of three parts in which part $\mathrm{A}$ is electrical characteristics and $\mathrm{B}$ and $\mathrm{C}$ include core and magnetic characteristics respectively.

The core loss is obtained from the following equation:

$$
P_{f e}=k_{f e} B^{\beta}{ }_{\text {max }} A_{c} l_{m}
$$

$\mathrm{K}_{\mathrm{fe}}$ is core loss coefficient which is different for various frequencies. $A_{c}$ is core cross-sectional area and $l_{m}$ is magnetic path length. The typical value of $\beta$ for ferrite core is $2.6<\beta<2.8$. $\mathrm{K}_{\mathrm{fe}}$ is drastically increased by increasing the frequency. In addition, $\mathrm{K}_{\mathrm{fe}}$ depends on core temperature and $\mathrm{B}_{\max }$. The dependency of $\mathrm{K}_{\mathrm{fe}}$ on frequency, $\mathrm{B}_{\max }$ and temperature can be obtained from core characteristics. In choosing the core when combined with different alloys, there has been always trade-off between saturated magnetic flux density and the core loss. Using materials with high $\mathrm{B}_{\text {sat }}$ leads to volume, size and price reduction. But these materials cause more core loss.

\section{Transformer Characteristic for Full-Bridge Converter}

To study the temperature rise in ferrite core and its effective parameters, a sample transformer for full bridge converter with two secondary windings and one primary winding is chosen which can be seen in Figure 2 [16].

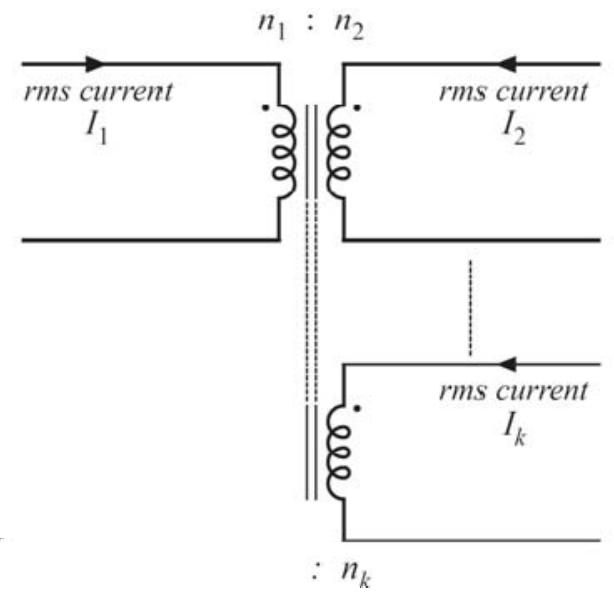

Figure 2. Transformer for full bridge converter with two outputs and one input. 
Table 1. Parameters of designed transformer for full bridge converter

\begin{tabular}{ll}
\hline Transformer frequency & $75 \mathrm{kHz}$ \\
\hline Turn ratio & $110: 5: 15$ \\
Duty cycle & 0.75 \\
Selected core & $\mathrm{EE} 40$ \\
$\mathrm{k}_{\mathrm{fe}}$ & $7.6 \mathrm{~W} / \mathrm{T}^{\beta} \mathrm{cm}^{3}$ \\
$\beta$ & 2.6 \\
$\mathrm{~K}_{\mathrm{u}}$ & 0.25 \\
$\rho$ & $1.724 \times 10^{-6} \Omega-\mathrm{cm}$ \\
$\lambda_{1}$ & $800 \mathrm{~V}-\mu \mathrm{sec}$ \\
$\mathrm{I}_{1}$ & $5.7 \mathrm{~A}$ \\
$\mathrm{I}_{2}$ & $66.1 \mathrm{~A}$ \\
$\mathrm{I}_{3}$ & $9.9 \mathrm{~A}$ \\
$\mathrm{I}_{\mathrm{tot}}$ & $14.4 \mathrm{~A}$ \\
$\mathrm{~B}_{\mathrm{max}}$ & $80 \mathrm{mT}$ \\
$\mathrm{n}_{1}$ & 22 \\
$\mathrm{n}_{2}$ & 1 \\
$\mathrm{n}_{3}$ & 3 \\
$\mathrm{P}_{\mathrm{fe}}$ & $230 \mathrm{~mW}$ \\
$\mathrm{P}_{\mathrm{cu}}$ & $3.89 \mathrm{~W}$ \\
$\mathrm{P}_{\text {tot }}$ & $4.12 \mathrm{~W}$ \\
\hline
\end{tabular}

The obtained parameters for this transformer are listed in Table 1. The core and winding losses calculated for transformer are equal to $230 \mathrm{~mW}$ and $3.89 \mathrm{~W}$ respectively. These losses can be used as heat generating source in modeling and simulating the transformer in ANSYS.

\section{Transformer Modeling in ANSYS}

In this part, transformer with two secondary windings is modeled in ANSYS software which is shown in Figure 3. The distance between each winding is $0.5 \mathrm{~mm}$. the primary winding is $20 \mathrm{~mm}$ long and $2 \mathrm{~mm}$ wide which this cross-sectional area includes 22 turns primary winding. This area for secondary winding is $20 \mathrm{~mm}^{2}(1 \mathrm{~mm} \times 20$ $\mathrm{mm})$ which is for one turn. Also, another secondary winding is $20 \mathrm{~mm}$ long and $0.5 \mathrm{~mm}$ wide which consists of three turns.

The electrical and thermal characteristics for different parts of transformer are listed in Table 2.

\section{Simulation Results}

In this simulation, it is assumed that the heat transfer between winding and core of the transformer has been naturally done (natural convection). So, the film coefficient varies from $10 \mathrm{~W} / \mathrm{m}^{2} \cdot{ }^{\circ} \mathrm{C}$ to $25 \mathrm{~W} / \mathrm{m}^{2} \cdot{ }^{\circ} \mathrm{C}$ when there is natural convection. The film coefficient is considered equal to $10 \mathrm{~W} / \mathrm{m}^{2} \cdot{ }^{\circ} \mathrm{C}$. The total cross-section of area is 70 $\mathrm{mm}^{2}$ and the power dissipation in this area is $3.89 \mathrm{~W}$. Therefore, the value of watt per square meter of area is equal to $55570 \mathrm{~W} / \mathrm{m}^{2}$ which is used for heat generation source in ANSYS. In Figure 4, temperature distribution

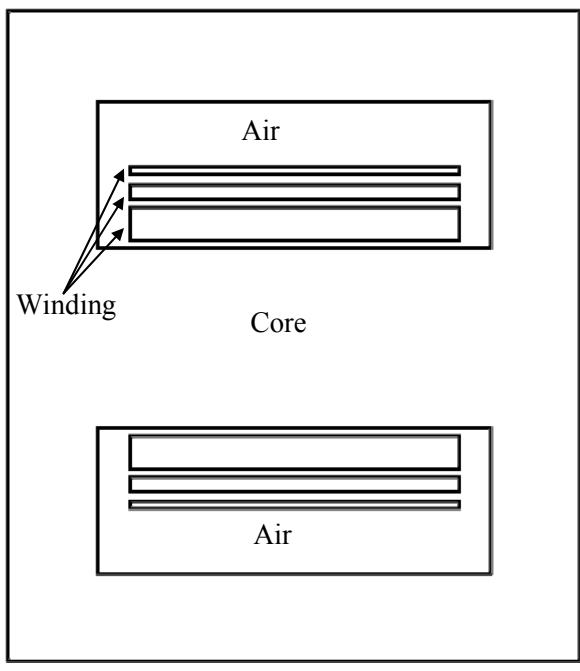

Figure 3. Modeled transformer in ANSYS.

Table.2 Electrical and thermal characteristics for different parts of transformer

\begin{tabular}{cccc}
\hline Parameter & \multicolumn{3}{c}{ Material } \\
\cline { 2 - 4 } & Copper & Ferrite Core & Air \\
\hline Density, $\rho\left[\mathrm{kg} / \mathrm{m}^{3}\right]$ & 8900 & 8900 & 1.09 \\
$\begin{array}{c}\text { Specific heat, } \mathrm{c}\left[\mathrm{J} / \mathrm{kg}^{\circ} \mathrm{C}\right] \\
\text { Thermal conductivity, } \\
\lambda[\mathrm{W} /(\mathrm{m} \cdot \mathrm{K})]\end{array}$ & 387 & 750 & 1006 \\
\hline
\end{tabular}

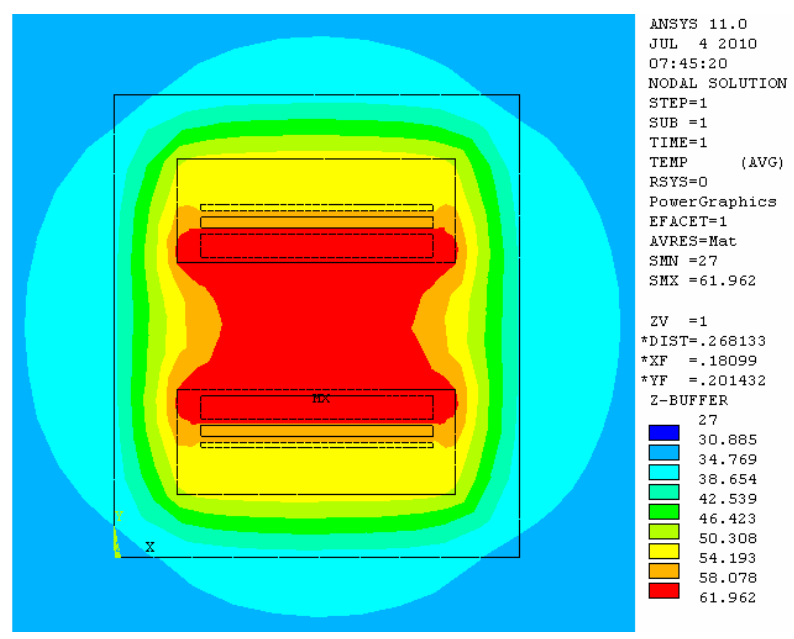

Figure 4. Thermal distribution in transformer.

through the transformer is shown. In this figure, the hottest point is primary winding and middle leg of ferrite core which is about $61.962^{\circ} \mathrm{C}$. By paying attention to this figure, it is clear that the core corners have lower temperature in comparison with other parts. It should be noticed that in this case, the secondary windings temperature are lower than that in primary one. The heat distribution in ferrite core is shown in Figure 5. 


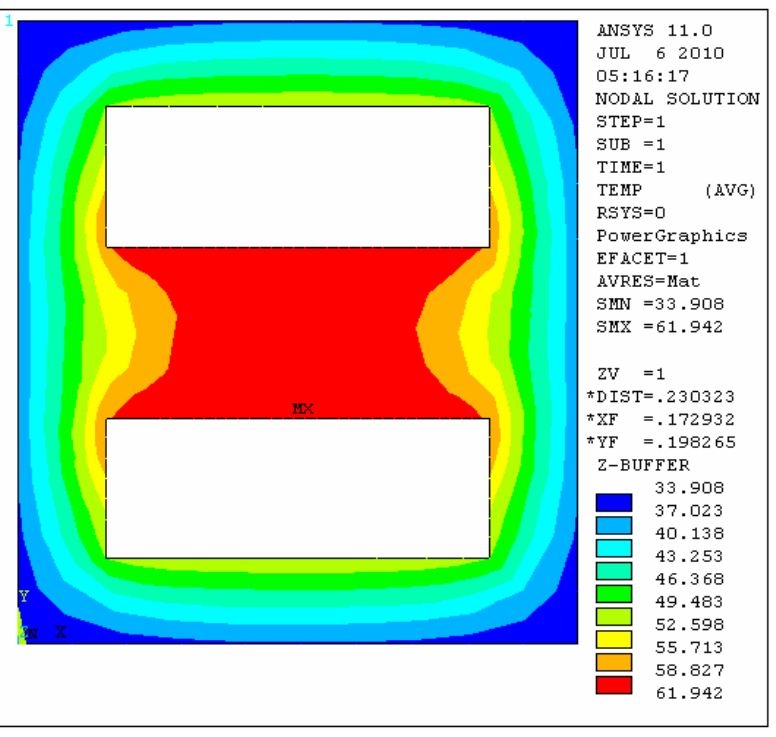

Figure 5. Thermal distribution in core.

Thermal flux in this case is shown in Figure 6 and it is maximized in primary winding corners which are about 428.69 W/m². Regarding this matter and according to Figure 4, it can be pointed out that the corners temperatures are lower than that in other parts.

\subsection{Variation of Flux Density}

In this part, the effect of flux density variation on temperature distribution in transformer has been investigated. For this purpose, the flux density is decreased from $80 \mathrm{mT}$ to $120 \mathrm{mT}$. According to Equation (10), the power loss is in inverse proportion with the square of flux density and by this change, the power loss is decreased 2.25 times.

The heat distribution for this condition is shown in Figure 7 in which the hottest point is about $55.309^{\circ} \mathrm{C}$. In

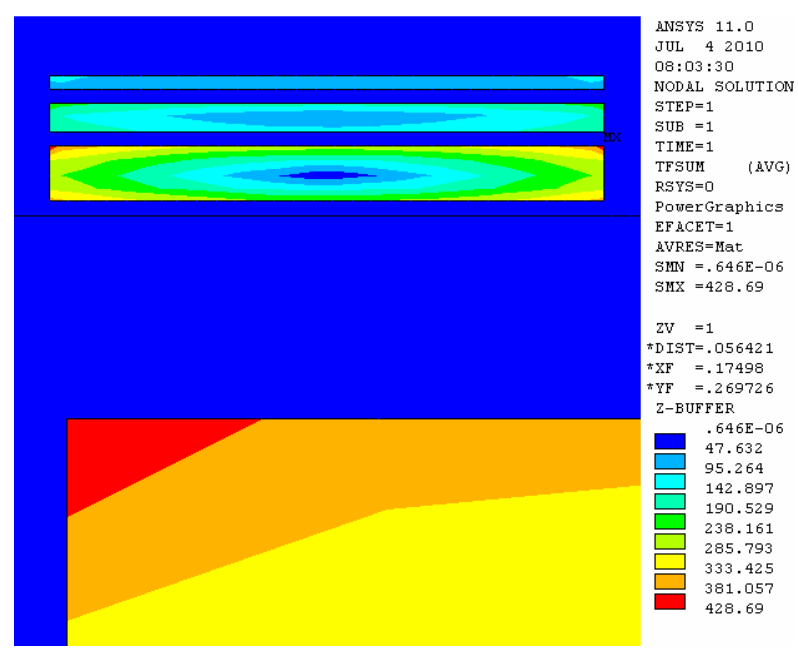

Figure 6. Thermal flux in transformer.

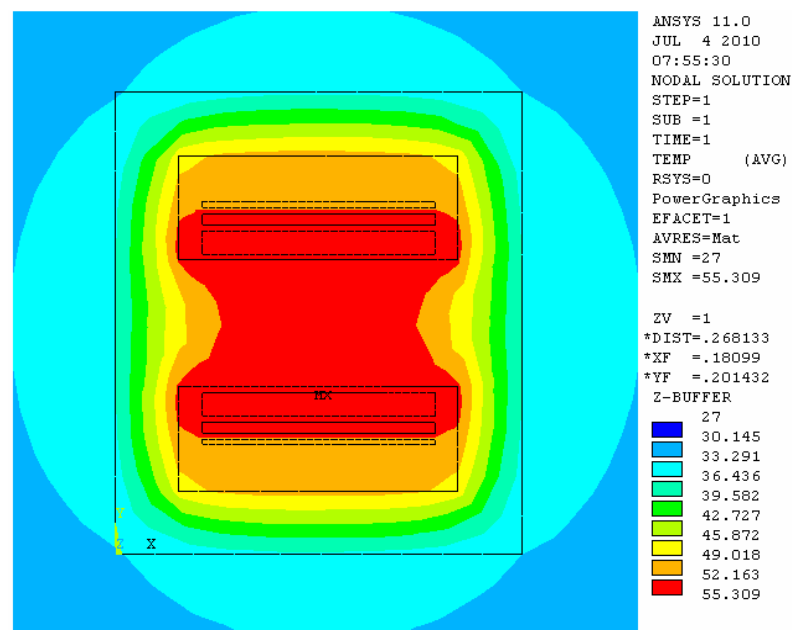

Figure 7. Thermal distribution in transformer (Decreasing flux density).

this case, one of the secondary windings temperatures (neighbor of primary winding) is approximately equal to primary winding temperature (the highest temperature).

\subsection{Variation of the Ambient Temperature}

In this case, it is supposed that the transformer is used in $40^{\circ} \mathrm{C}$ temperature. So, it is observed that the maximum temperature inside the transformer has been slightly increased and has reached to $61.971^{\circ} \mathrm{C}$. In this case, the maximum temperature is in primary winding and core middle leg as well.

By comparing Figure 4 with Figure 8, we can make the conclusion that regarding the proximity of core sides to heat source and warmer environment, the sides' temperature are higher than that in up and down of core.

\subsection{Using a Fan to Cool the Winding}

The film coefficient varies from $50 \mathrm{~W} / \mathrm{m}^{2} \cdot{ }^{\circ} \mathrm{C}$ to 120 $\mathrm{W} / \mathrm{m}^{2} \cdot{ }^{\circ} \mathrm{C}$ when there is forced convection. For this case the film coefficient has been changed from $10 \mathrm{~W} / \mathrm{m}^{2}{ }^{\circ} \mathrm{C}$ to $50 \mathrm{~W} / \mathrm{m}^{2} \cdot{ }^{\circ} \mathrm{C}$. The temperature distribution is shown in Figure 9.

By using the fan, almost all windings have the same temperature of $52.508^{\circ} \mathrm{C}$. By comparing this figure with Figure 4, it can be understood that using the fan leads to winding temperature reduction from $61.962^{\circ} \mathrm{C}$ to $52.508^{\circ} \mathrm{C}$. By this analysis, the appropriate fan can be chosen.

\subsection{Using a Fan to Cool the Core}

In this case, it is supposed that core is cooled by a fan (the film coefficient is $50 \mathrm{~W} / \mathrm{m}^{2} .{ }^{\circ} \mathrm{C}$ ). The heat distribution in this condition is plotted in Figure 10. According to this figure, the core ambient temperature is almost 


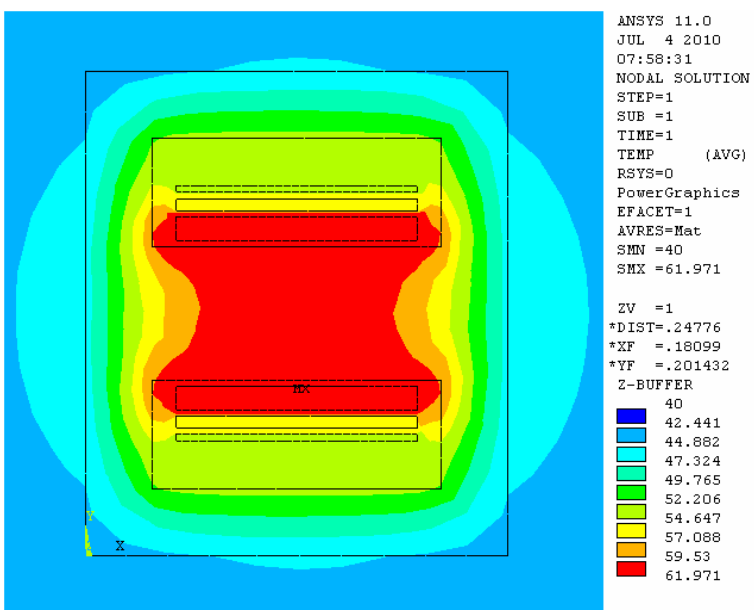

Figure 8. Thermal distribution in transformer (Increasing the ambient temperature).

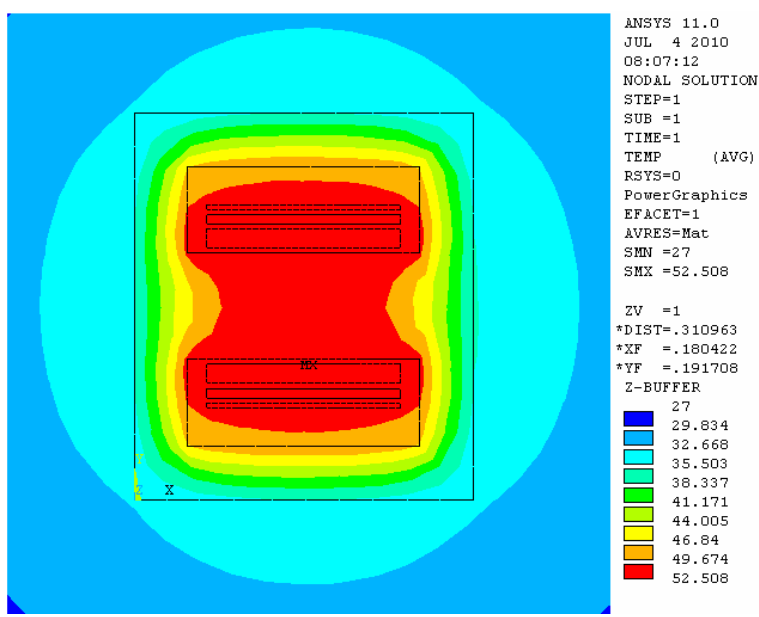

Figure 9. Thermal distribution in transformer (Using fan to cool the winding).

equal. This figure shows that changing the film coefficient causes suitable increase in core temperature $\left(61.95^{\circ} \mathrm{C}\right)$.

\subsection{Variation of Thermal Conductivity}

On of the other studied parameters is thermal conductivity that it is changed from $0.004 \mathrm{~W} /(\mathrm{m} \cdot \mathrm{K})$ to $0.008 \mathrm{~W} /(\mathrm{m} \cdot \mathrm{K})$. Thermal distribution for this mode is shown in Figure 11.

This figure shows that the thermal conductivity has a little effect $\left(61.95^{\circ} \mathrm{C}\right)$ on the temperature but the thermaldistribution around the transformer is uniform as a circle from centre of transformer.

\section{Conclusions}

In this paper, the thermal behavior of different cores has been studied. For this purpose, first for a typical trans-

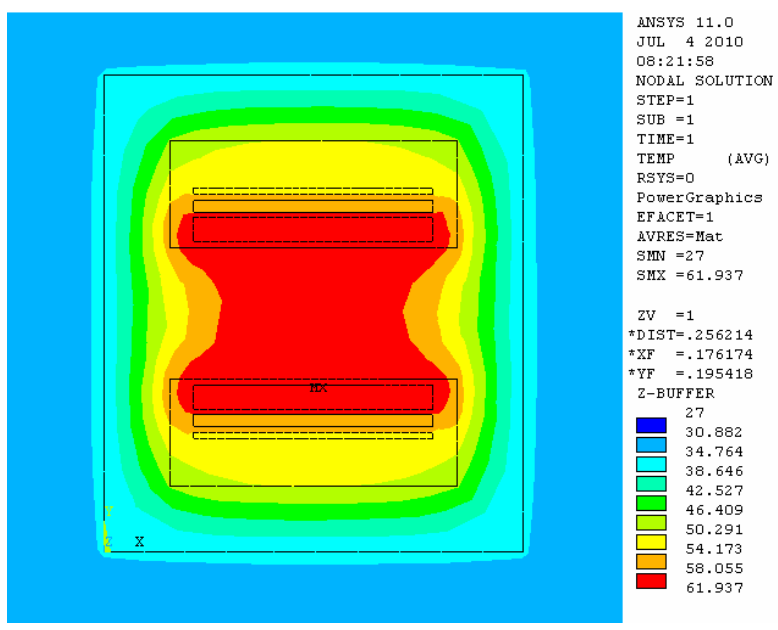

Figure 10. Thermal distribution in transformer (Using fan to cool the core).

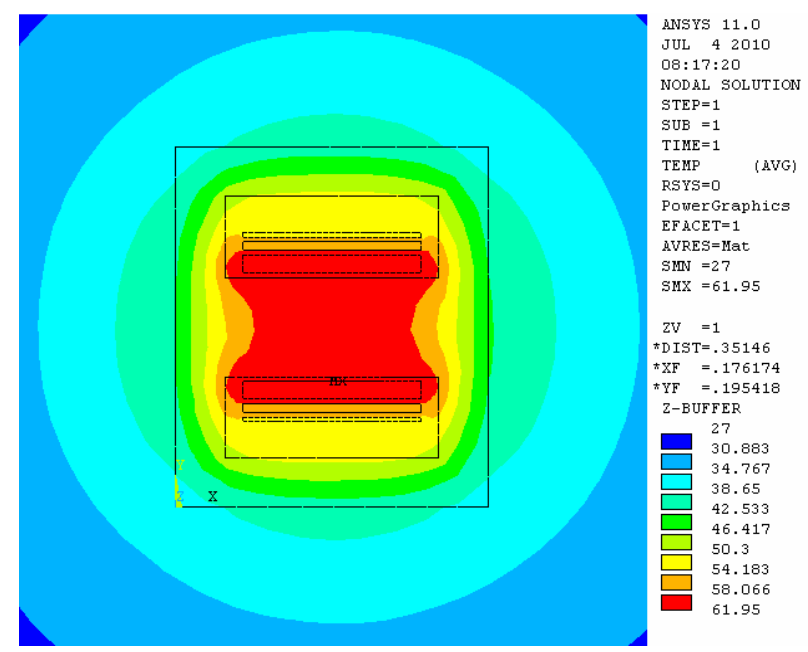

Figure 11. Thermal distribution in transformer (Increasing thermal conductivity).

former, the generation heat is computed then it is totally simulated in ANSYS software. In this simulation, the thermal analysis and heat distribution were studied. Then, the effects of parameters such as flux density, winding loss value, the film coefficient have been investigated.

According to obtained results, in case of using a fan to cool the winding, the maximum temperature of transformer has been decreased. Furthermore, it was shown that by decreasing the flux density, the temperature of the hottest point in transformer has been decreased which is due to the power loss reduction in windings. Moreover, it is explained in the paper that the core temperature can be controlled by increasing the film coefficient (by using a fan). As a result, with the findings of this analysis, an appropriate fan can be chosen in order to cool the whole transformer. In the paper, it is also elaborated that the 
core corners have the lower temperature in comparison with other parts. This part has the maximum thermal flux as well.

\section{REFERENCES}

[1] S. N. Talukdar and J. R. Bailey, "Hysteresis Models for System Studies," IEEE Transactions on Power Apparatus and Systems, Vol. 95, No. 4, 1976, pp. 1429-1434.

[2] C. C. Wong, "A Dynamic Hysteresis Model," IEEE Transactions on Magnetics, Vol. 24, No. 2, 1988, pp. 1966-1968.

[3] D. R. Bennion, H. D. Crane and D. Nitzan, "Digital Magnetic Logic," McGraw-Hill, New York, 1969.

[4] F. Presiach, "On the Magnetic Aftereffect," Zeitschrift für Physik, Vol. 94, 1935, pp. 227-302.

[5] R. D. Vecchio, “An Efficient Procedure for Modeling Complex Hysteresis Processes in Ferromagnetic Materials," IEEE Transactions on Magnetics, Vol. 16, No. 5, 1980, pp. 809-811.

[6] D. L. Atherton, B. Szpunar and J. A. Szpunar, "A New Approach to Presiach Diagrams," IEEE Transaction on Magnetics, vol. 23, No. 3, May 1987, pp. 1856-1865.

[7] B. Szpunar, D. Atherton and M. Schonbachler, "An Extended Presiach Model for Hysteresis Processes," IEEE Transactions on Magnetics, Vol. 23, No. 5, 1987, pp. 3199-3201.
[8] J. P. Vandelac and P. D. Ziogas, "A Novel Approach for Minimizing High Frequency Transformer Copper Losses," IEEE Transaction on Power Electronics, Vol. 3, No. 2, 1988, pp. 266-277.

[9] B. Carsten. "High Frequency Conductor Losses in Switched Mode Magnetic," in Proc. HFPC Con\$ Ventura, CA: Intertec Communications Inc., May 1986.

[10] Power Conversion and Line Filter Applications.

[11] Design of low profile high frequency transformers-A new tool in SMPS design-. Philips Magnetic Products. Application note. May.1990.

[12] Kool Mu Powder Cores Data Book. Magnetics.

[13] L. M. Escribano, R. Prieto, J. A. Cobos and J. Uceda, Thermal Modeling of Magnetic Components: A Survey," Proceeding of $28^{\text {th }}$ Annual Industrial Electronics Society Conference of the IEEE, Sevilla, 5-8 November 2002, pp. 1336-1341.

[14] L. M. Escribano, R. Prieto, J. A. Oliver, J. A. Cobos and J. Uceda, "Analytical Thermal Model for Magnetic Components," Proceedings of 34th Annual Power Electronics Specialist Conference of the IEEE, 2003, pp. 861-866.

[15] J. C. S. Fagundes, A. J. Batista and P. Viarouge, "Thermal Modeling of Pot Core Magnetic Components Used in High Frequency Static Converters," IEEE Transactions on Magnetic, Vol. 33, No. 2, March 1997, pp. 1710-1713.

[16] R. W. Ericksonand D. Maksimo, "Fundamentals of Power Electronics,” 2nd Edition, Springer, Berlin, 2002.

\section{Nomenclature}

$\begin{array}{ll}\rho & \text { Wire effective resistivity }(\Omega-\mathrm{cm}) \\ I_{t o t} & \text { Total rms winding current, ref to primary (A) } \\ n 2 / n 1, n 3 / n 1, \text { etc } & \text { Desired turns ratios }(\mathrm{V}-\mathrm{sec}) \\ \lambda_{1} & \text { Applied primary volt-sec } \\ P_{t o t} & \text { Allowed total power dissipation }(\mathrm{W}) \\ K_{u} & \text { Winding fill factor } \\ \beta & \text { Core loss exponent } \\ K_{f e} & \text { Core loss coefficient }\left(\mathrm{W} / \mathrm{cm}^{3} \mathrm{~T}^{\beta}\right) \\ A_{c} & \text { Core cross-sectional area }\left(\mathrm{cm}^{2}\right) \\ W_{A} & \text { Core window area }\left(\mathrm{cm}^{2}\right) \\ M L T & \text { Mean length per turn }(\mathrm{cm}) \\ 1_{e} & \text { Magnetic path length }(\mathrm{cm}) \\ A_{w 1}, \ldots & \text { Wire areas }\left(\mathrm{cm}^{2}\right) \\ \Delta B & \text { Peak ac flux density }(\mathrm{T})\end{array}$

